\title{
Overview On The Epidemiological Situation And The Brucellosis' Control, Between 1974 -2014, In West Bank, Palestine
}

\author{
Elena AWWAD ${ }^{1,2}$, Younis SBEIH ${ }^{5}$, Osama AWWAD ${ }^{2}$, Mohammad FARRAJ ${ }^{3}$, Tamer ESSAWI ${ }^{3}$, \\ Kamel ADWAN ${ }^{4}$, Asad MANASRA ${ }^{2}$, Stelian BĂRĂITĂREANU ${ }^{1}$, Maria Rodica GURĂU ${ }^{1}$ and Doina DANEȘ ${ }^{1 *}$ \\ ${ }^{1}$ Faculty of Veterinary Medicine. University of Agronomic Science and Veterinary Medicine of Bucharest, \\ Romania, Splaiul Independentei 105, sector 5, 050097, Bucharest, Romania \\ ${ }^{2}$ Central Veterinary Laboratory. General Directorate of Veterinary Services and Animal Health. Ministry \\ of Agriculture, Ramallah, Palestine \\ ${ }^{3}$ Master Program in Clinical Laboratory Science, Birzeit University, Birzeit, Palestine \\ ${ }^{4}$ Department of Biology and Biotechnology, An-Najah National University, Nablus, Palestine \\ ${ }^{5}$ Office of UNDP (United Nations Development Programme) Organization, Ramallah, Palestine
}

*corresponding author: danes.doina@gmail.com

Bulletin UASVM Veterinary Medicine 75(1)/2018

Print ISSN 1843-5270; Electronic ISSN 1843-5378

doi:10.15835/buasvmcn-vm:006317

\begin{abstract}
Brucellosis in Palestine is a problem of huge concern due to the human health impact, as consequence of the high prevalence level of the infection in livestock. The purpose of the research was to give an insight of the current epidemiological peculiarities of the brucellosis in livestock versus human population. This paper processed all data of the brucellosis' control program and the epidemio-surveillance results. The seroprevalence of brucellosis in 1999 , was $18 \%$ in sheep and goat and $80 \%$ in flocks, and more than 800 human cases. As result of mass vaccination, with $80 \%$ coverage vaccination rate, the decrease of brucellosis was registered: $4.8 \%$ in animals and $40 \%$ in flock; human infection less than 200 cases. The main conclusion of our study is that the vaccination must be in force up to the level of prevalence, below $2 \%$ in animals, allowing the next step, the "test-and-slaughter" strategy, toward the eradication goal.
\end{abstract}

Keywords: Brucellosis control program, epidemiology, outbreak

\section{Introduction}

Brucellosis is most important zoonotic disease worldwide and in Mediterranean region, there is evidence of its increased prevalence (Doganay and Aygen, 2003; Gul and Khan, 2007). This disease deserves special attention because has potential impact on various aspects of lives (i.e., human and animal health, economic development, agriculture, trade, and tourism) and remains a worldwide veterinary and medical problem, threatening the health and economic situation of affected regions (FAO, 2010; WHO, 1999). The brucellosis of small ruminants, caused by Brucella melitensis is still widespread, sourcing human illness, primarily by consumption of contaminated dairy products or by occupational exposure to infected livestock (Doganay and Aygen, 2003; Kaoud et al., 2010; Saleem et al., 2010; Sanco, 2001; Zvizdic et al., 2006). Several brucellosis eradication programs have been launched in many countries, but the success of these programs did not reached the expected level. These programs were designed considering to carry actions as identification of small ruminants, controlling their circulation, identification of infected flocks and their stemptout, vaccination and serological monitoring of 
remaining animals. (FAO, 2010; Refai, 2002). Successful campaigns have been carried out against the brucellosis of small-ruminants based on test-and-slaughter policy, and eradication has been achieved in many countries. However, in Palestine, a similar policy has failed to implement for control brucellosis in small ruminants because there are many factors (especially budgetary constraints and the type of husbandry) that impact the effectiveness of the campaign (Blasco, 2010; Blasco and Molina-Flores 2011; FAO 2010). In Palestine, sheep-and-goat farming is the largest sector of food-animal production and livestock farming is an essential part of life owing to historical/cultural reasons and geographical/ natural conditions. The flocks are kept for producing milk that mainly is used for production of white homemade cheese. Usually, milking is done by hand (MOA 2013a, 2013b, 2014a, 2014b).

The objective of this paper is to give an updated overview of control brucellosis since 1974 and to characterize the epidemiological and epizootic situation based on old and recent limited official and unpublished data from archive of Palestinian Ministry of Agriculture and reports of the United National Development Program (UNDP), the last one being for long period of time responsible for implementation brucellosis control program in order to customize recommendation for next control measures. There are no enough accessible, reliable data concerning the epidemiological and epizootological status of brucellosis in Palestine, by missing previous studies assesing the result of brucellosis control mesures in Palestine.

\section{Materials and methods}

The data of the brucellosis' control program and the epidemio-surveillance results belong to the yearly unpublished or published reports of the Directorate of Veterinary Services and Animal Health, to the reports of UNDP organization and from other reports of international organizations. All data were processed in Microsoft Excel.

\section{Results and discussions}

\section{Attempt to control brucellosis in small ruminants}

Since 1974 were implemented vaccination strategies for all young animals. Since 1982 have been vaccinated only young sheep and goat females (2 - 7 month old) with Rev 1, subcutaneously, full dose. Vaccination has been compulsory and free of charge for owners.

In 1992, Palestinian veterinary service initiated a partial test and slaughter policy, but short time after it has been aborted due to financial burden (VSPT, 1994). In 1995-1996 the prevalence of brucellosis in sheep and goats flocks was $14 \%$. From 1985 to 1998 weare vaccinated yearly, subcutaneous, about 25000 of small ruminants, the coverage being no more than 20\% of population in West Bank (VSPT, 1994).

Since 1998, the Palestinian Ministry of Agriculture in collaboration with UNDP/PAPP has been implementing the Palestinian Brucellosis Control Program (PBCP) according to the international guidelines (FAO-WHO-OIE, 2005). The activities were implemented in two phases, until 2005 and extended for the next 5 years, until 2010 (Domingo et al., 2000).

The prevalence of seropositive reactors against brucellosis in 1999, was 18\% in sheep and goats, $80 \%$ in flocks, and in humans have been registered more than 800 cases.

The tool of brucellosis control project was mass vaccination of small ruminants every 2 years over 10 years, in order to reduce the number of animal and human cases to the adequate low level, building-up and improving meantime the veterinary service capability.

\section{Achievements of the Palestinian \\ Brucellosis Control Program}

Registration of the farms: every farm was assigned to a different FIN (Farm Identification Number), which consists of six digits: the first digit is a letter that stands for the district, the next two digits stand for the village or the locality within the district, the last three digits it stand for the farm within the village or veterinary location (Domingo et al., 2000).

Vaccination of the animals: all sheep and goats over one year old, sex regardless, outside the pregnant ones, has been vaccinate once each 2 years. Newborn and one-year-old animals, were vaccinated yearly. The first mass vaccination was done from March to August 1999 using Rev 1 vaccine (Laboratorios Ovejero, Leon, Spain), full dose $1 \times 10^{9}$, by conjunctival route (eye drop). It were vaccinated 871,839 (99.3\%) sheep and goats: $7.5 \%$ of the total mature females were vaccinate after delivery (Tab. 1 ). 
Table 1. Number of vaccinated animals between 1999-2014 (GDVSAH, 2014)

\begin{tabular}{ccccccc}
\hline Years & $\begin{array}{c}\text { No of } \\
\text { animals } \\
\text { (all sheep } \\
\text { and goat) }\end{array}$ & $\begin{array}{c}\text { No of } \\
\text { vaccinated } \\
\text { animals }\end{array}$ & Type of vaccination & $\begin{array}{c}\text { Covering } \\
\text { rate (\%) }\end{array}$ & $\begin{array}{c}\text { No of } \\
\text { abortion } \\
\text { due } \\
\text { Brucella }\end{array}$ & $\begin{array}{c}\text { No of } \\
\text { human } \\
\text { cases }\end{array}$ \\
\hline 1998 & 884567 & 110560 & Only young & 12 & 25 & 837 \\
\hline 1999 & 877515 & 831681 & Mass vaccination & 95 & 15 & 747 \\
\hline 2000 & 865343 & 277337 & Only young & 32 & 11 & 304 \\
\hline 2001 & 845765 & 221445 & Mass vaccination & 26 & 8 & 273 \\
\hline 2002 & 838542 & 344341 & Only young & 41 & 10 & 166 \\
\hline 2003 & 942300 & 820016 & Mass vaccination & 87 & 7 & 267 \\
\hline 2004 & 934570 & 352222 & Only young & 38 & 8 & 153 \\
\hline 2005 & 1103742 & 722627 & Mass vaccination & 65 & 9 & 115 \\
\hline 2006 & & Finish phase I, not extended yet phase II, absence of vaccine & \\
\hline 2007 & 1174363 & 415658 & Mass vaccination & 35 & 10 & 206 \\
\hline 2008 & 801017 & 665234 & Mass vaccination & 83 & 8 & 199 \\
\hline 2009 & 759410 & 198620 & Only young & 26 & 9 & 195 \\
\hline 2010 & 860138 & 665585 & Mass vaccination & 77 & 7 & 206 \\
\hline 2011 & 972535 & No vaccine & Only young & 0 & 11 & 179 \\
\hline 2012 & 954120 & About & Mass vaccination & About 26 & 15 & 148 \\
\hline 2013 & 943000 & No vaccine & Only young & 0 & 17 & 244 \\
\hline 2014 & 927600 & About & Mass vaccination & About 27 & 16 & 280 \\
\hline
\end{tabular}

\section{Sero-monitoring of vaccinated animals during vaccination campaign}

The immune answer has been checked over the vaccination campaign, using Rose Bengal Test (RBT) and Complement Fixation Test (CFT), in randomly selected animals, 20-30 days post vaccination: $60-80 \%$ of the flocks expressed specific immune response (GDVSAH, 2014).

\section{Human and animals brucellosis}

According to the reports, Ministry of Health it registered a significant decrease of human cases of brucellosis: from 837 cases of human infection in 1998, to less than 200 after implementation of project (Fig. 1). Also it decreased the rate of aborted animals due to brucellosis: until 1998 were more than 25 cases yearly, but during the vaccination have been registred under 10 cases yearly (Fig. 2).

Based on the results of sero-surveillance, brucellosis decreased among individuals and flocks, as fallow: in 1998 was $18 \%$ among animals and $80 \%$ among flocks, but after 5 years of vaccination it become $6 \%$ and after 9 years was 5\% . (Tab. 2).

At the end of the Control Program, as result of mass vaccination, with $80 \%$ coverage vaccination rate, the decrease of brucellosis succeeded: $4.8 \%$ in animals and $40 \%$ in flock and human infection less than 200 cases. However, after the closure of the program in 2014, brucellosis prevalence is increasing again. For the success of an eradication program for Brucella melitensis 


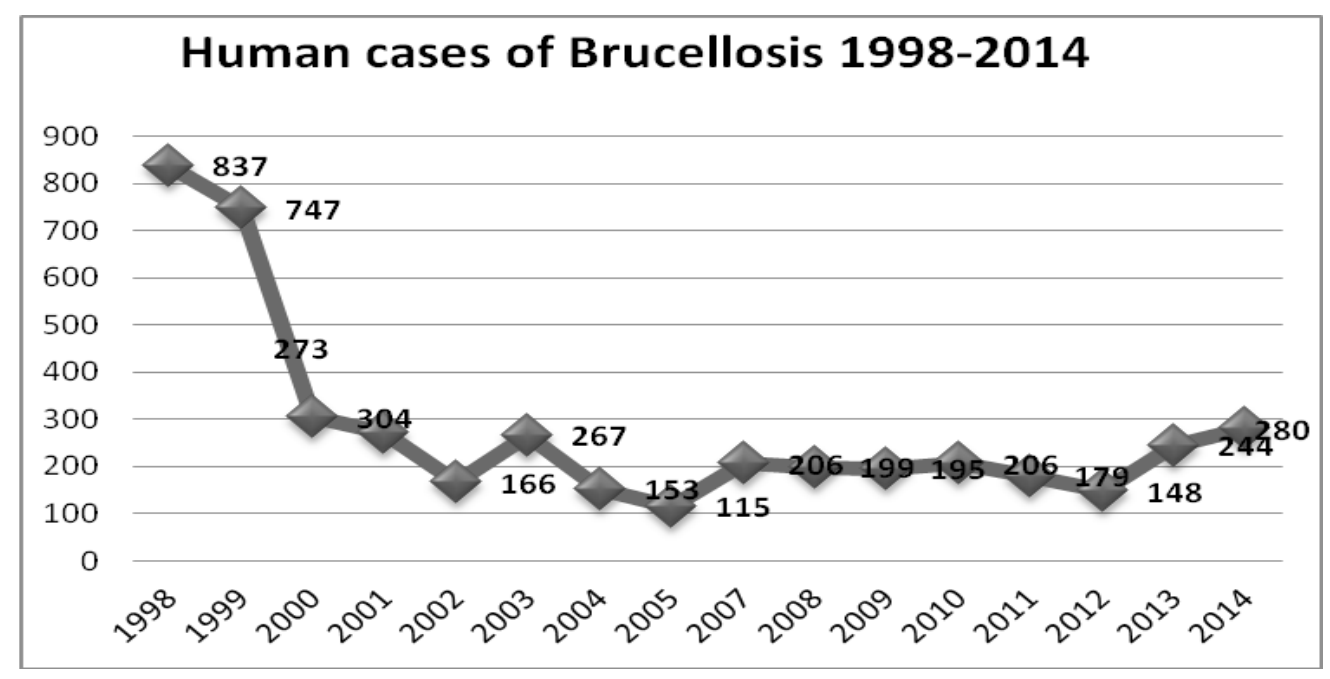

Figure 1. The prevalence of brucellosis in humans during the vaccination campaign 1998-2014

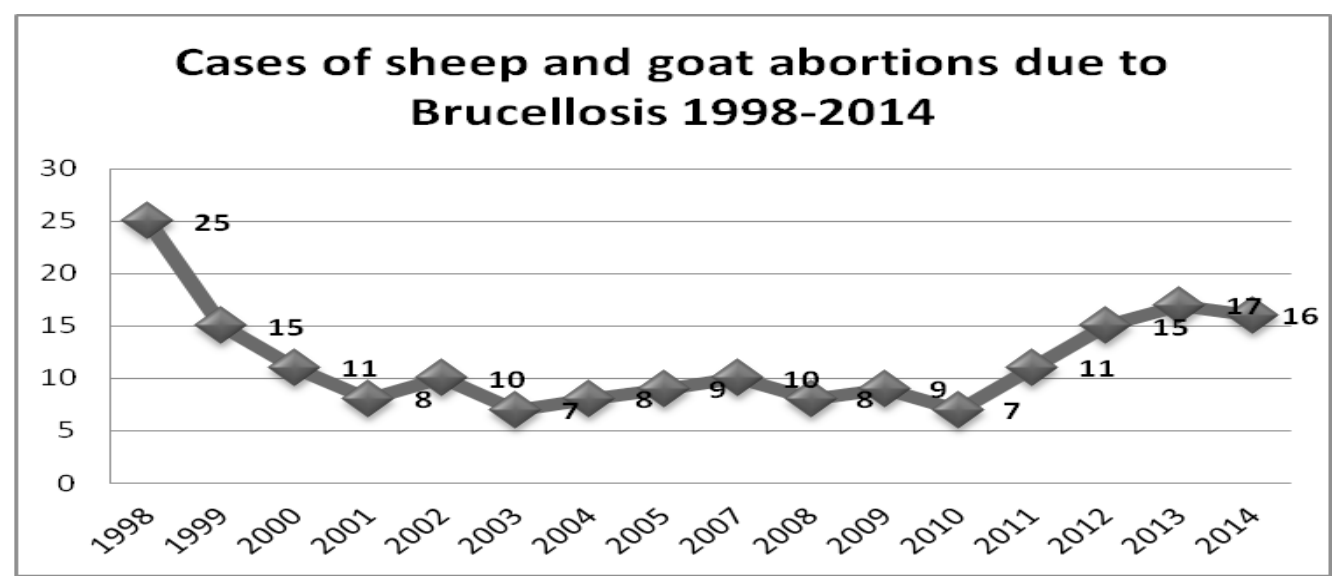

Figure 2. Dinamic of sheep and goat abortions due to brucellosis from 1998 to 2014

Table 2. Prevalence of antibodies against Brucella melitensis during the 15 years of Brucellosis Control Project

\begin{tabular}{|c|c|c|c|c|c|c|c|c|c|}
\hline \multirow[b]{2}{*}{ Location } & \multicolumn{3}{|c|}{1999} & \multicolumn{3}{|c|}{2005} & \multicolumn{3}{|c|}{2009} \\
\hline & $\begin{array}{c}\text { No of } \\
\text { samples }\end{array}$ & $\begin{array}{c}\text { By } \\
\text { animals }\end{array}$ & $\begin{array}{c}\text { By } \\
\text { flocks }\end{array}$ & $\begin{array}{c}\text { No of } \\
\text { samples a }\end{array}$ & $\begin{array}{c}\text { By } \\
\text { animals } \mathrm{f}\end{array}$ & $\begin{array}{c}\text { By } \\
\text { flocks }\end{array}$ & $\begin{array}{c}\text { No of } \\
\text { samples }\end{array}$ & $\begin{array}{c}\text { By } \\
\text { animals }\end{array}$ & By flocks \\
\hline (RBT) & & & & & & & 15000 & $5 \%$ & $38 \%$ \\
\hline $\begin{array}{l}\text { West Bank } \\
\text { (CFT) }\end{array}$ & 15000 & $18 \%$ & $82 \%$ & 12790 & $6 \%$ & $48 \%$ & 15000 & $4.8 \%$ & $36 \%$ \\
\hline
\end{tabular}


endemic infection, it is necessary to reduce the individual prevalence of the infection and at the level of the herds too, below the level recorded at the end of the analyzed program; this medical situation must be supported by a package of administrative measures that will make it possible to control the movement of animals, so that it is possible to move to the next level, respectively "free of disease/infection".

To understand and control epizootic and epidemic processes caused by Brucella melitensis, to discover his epidemic links and to discriminate field strains toward vaccine strain, would be recommended to characterize the genome of the field strains.

It is proved by the epidemiological peculiarities of disease a relationship between the vaccination coverage and the incidence of brucellosis in humans and animal (Jokhdar, 2009; Blasco, 2010). It is widely accepted that in areas where brucellosis is endemic in small ruminants, vaccination is the only suitable method for disease's control. Where the prevalence of brucellosis in sheep and goats flocks is high, vaccination of the entire population of animals is the most-effective means of controlling brucellosis (Blasco 2010; Blasco and Molina-Flores, 2011; Jokhdar, 2009). Vaccination of animals has a direct impact on the incidence of brucellosis in both, animals and humans, due to an increase of the number of immune animals, and to the abortion decrease and, therefore, excreting the organism. (Nyamdorj et al., 2012; Arnaudov, 2014; Donev et al., 2010; El-Ghitany et al., 2014; Gunawardena et al., 2013; Yumuka and O'Callaghan, 2012; Amarnath, 2008).

The result of this study show huge benefit from implementation of brucellosis control program. Among sheep and goats, the seroprevalence of brucellosis was 18\% in 1999, $80 \%$ flocks being contaminated, and in humans have been reported more than 800 cases. At the end of the Palestinian Brucellosis Control Program, in 2010, as result of comprehensive mass vaccination, with about $80 \%$ covering vaccinated rate, show significantly decrease of brucellosis, its $4.8 \%$ in animals and $40 \%$ in flock; in humans, it have been registred bellow 200 cases, but after finishing well organized and financially supported progamm, unfortunately, in the last year of BPCP, the human and animal brucellosis cases started again to increase and the problem is remaining. To understand and control epizootic and epidemic processes caused by Brucella melitensis, it will be important to identify and conduct genotyping of Brucella strains circulating in Palestine, as well as to differentiate between field and vaccine strains (FAO, 2010).

Controlling of brucellosis requires planning on the national level, and Palestine alone, without international support, cannot prevent and control any communicable diseases in general and zoonoses (brucellosis) in particular. Financial well-supported brucellosis control programs, regardless of the magnitude of brucellosis incidence, are necessary for eradication and control of brucellosis.

In order to hold control on the brucellosis situation in country, it is requested a close cooperation with livestock owners', a reliable collection of data on they everyday practices as well as their awareness, including fundamental information such as local behaviour and animal trading practices; these will provide support for the primary health care services, for the animal production, for the food safety and a most efficient ways to reduce the prevalence of human brucellosis cases. (Diaz Aparicio, 2013; Dean et al., 2012; FAO, 2010; Lopes et al., 2010; EU, 2009; Jokhdar, 2009; Gul and Khan, 2007).

Close cooperation between laboratories, veterinary services and local health departments are a prerequisite for a successful brucellosis control and can be used to set up an efficient and effective monitoring program. Overall, collaboration between all countries in the Mediterranean region is necessary, with technical and financial support of appropriate brucellosis control and eradication programmes from the European Commission, OIE, FAO and other international organizations.

\section{Conclusion}

Vaccination using Rev1 should be related to the epidemiological : when brucellosis seroprevalence reached $2 \%$ in animals, the implementation of the "test-and-slaughter" strategy would be more likely to lead to the eradication of brucellosis. The collaboration of the Veterinary Services and Public Health Services with farmers is essential for the efficient implementation of brucellosis control and for 
the eradication strategies. According to the quantity of disease, it is necessary careful herd management, the control of animal movement between neighboring countries, and the implementation of basic biosecurity measures. Continuous surveillance and reporting are mandatory in monitoring the presence/absence of brucellosis and the efficacy of control programmes.

Acknowledgments. This research did not receive any specific grant from funding agencies in the public, commercial, or not-for-profit sectors.

\section{REFERENCES}

1. Amarnath S, (2008). Brucellosis in India - a review. J Biosci, 33: 539-547.

2. Arnaudov A, (2014). Epizootical and epidemiological features of brucellosis in Bulgaria. J BioSci Biotech, 141143.

3. Blasco JM, Molina-Flores B, (2011). Control and eradication of Brucella melitensis infection in sheep and goats. Vet Clin N Am (Food Anim Pract), 27(1): 95-104.

4. Blasco J, (2010). Control and eradication strategies for Brucella melitensis infection in sheep and goats. Prilozi, 31(1): 145-165.

5. Dean A, Crump L, Greter H, Schelling E, Zinsstag J, (2012). Global Burden of Human Brucellosis: A Systematic Review of Disease Frequency. PLoS Negl Trop Dis. Doi: 10.1371/ journal.pntd.0001865.

6. Diaz Aparicio E, (2013). Epidemiology of brucellosis in domestic animals caused by Brucella melitensis, Brucella suis and Brucella abortus. Rev SCI tech Off Int Epiz, 32(1): 53-60.

7. Doganay M, Aygen B, (2003). Human brucellosis: an overview. Int J Infect Dis, 7: 173-182.

8. Domingo E, Ortiz A, Shuaibi A, Hassouneh M, (2000) Palestinian Brucellosis Control Program (PBCP). Proceedings of the 9th International Symposium on Veterinary Epidemiology and Economics, 2000. Available at www.sciquest.org.nz.

9. Donev D, Karadzovski Z, Kasapinov B, Lazarevik V, (2010) Epidemiological and public health aspects of brucellosis in the republic of Makedonia. Sec Biol Med Sci, MASA, 31(11): 33-54.

10. El-Ghitany E, Omar S, Abaza A, Hassan E, Abd El-Wahab E, (2014). Trends in the Epidemiology of Brucellosis in a Highly Afflicted Region in Egypt: A 16 Year Experience (1997-2012). Int J Trop Dis Health, 4(2): 250-271.

11. EU (European Commission Health and Consumers Directorate-General), (2009). Working Document on Eradication of Bovine, Sheep and Goats Brucellosis in the EU SANCO/6095/2009 https://ec.europa.eu/food/sites/ food/files/animals/docs/reg-com_ahw_20091130_sum. pdf Accessed 15.09.17.
12. FAO-WHO-OIE, (1995). Guidelines for a Regional Brucellosis Control Programme for the Middle East. France.

13. FAO, (2010). Brucella melitensis in Eurasia and the Middle East. FAO Animal Production and Health Proceedings. No. 10. Rome.

14. GDVSAH (General Directorate of Veterinary Services and Animals Health), (2014).Yearly reports 1998-2014. Archive, unpublished.

15. Gul T, Khan A, (2007). Epidemiology and epizootology of brucellosis: A review. Pakistan Veterinary Journal, 27: 145-151.

16. Gunawardena N, Chandrasekara S, Hettiarachchi G, Perera S, Jagoda S, Fernando P, Gamage D, Ubeyrathne K, (2013). Brucellosis in Sri Lanka: A review of the epidemiology and control strategies, and recommendations for future control strategies. South Asia Regional One Health Symposium.http://www.onehealthnetwork.asia/sites/ onehealthnetwork.asia/files/upload/Sri\%20Lanka\%20 CIP_Brucellosis_131202.pdf Accessed 15.09.17.

17. Jokhdar H, (2009). Brucellosis in Saudi Arabia: Review of Literature and an Alarming Case Report in a Hospital in Jeddah. Med J Cairo Univ, 77(3): 47-55.

18. Kaoud A, Zaki M, El-Dahshan A, Nasr S, (2010). Epidemiology of brucellosis among farm animals. Nature and Science, 8: 190-197.

19. Lopes L, Nicolino R, Haddad J, (2010). Brucellosis - Risk Factors and Prevalence: A Review. OJVM, 4: 72-84.

20. MOA (Ministry of Agriculture of Palestina), (2013a). Action Plan of the National Agricultural Strategy "Shared Vision" 2011-2013, www.apis.ps/up/1323689642.pdf Accessed 15.09.17.

21. MOA (Ministry of Agriculture of Palestina), (2013b). From shared vision to action plan. www.lacs.ps/ documentsShow.aspx?ATT_ID Accessed 15.09.17.

22. MOA (Ministry of Agriculture of Palestina), (2014a). Yearly report the Department of Damage Documentation. Archive, unpublished.

23. MOA (Ministry of Agriculture of Palestina), (2014b), Agricultural Sector Strategy "Resilience and Development". www.apis.ps/up/1417423273.pdf Accessed 15.09.17.

24. Nyamdorj S, Batbaatar V, Erdenebaatar J, Yang Zheng Qi, (2012). An Epidemiological Situation of an Animal Brucellosis in Mongolia. European Researcher, 27: 8-2.

25. Refai M, (2002). Incidence and control of brucellosis in the Near East region. Veterinary Microbiology, 90: 81-110.

26. Saleem N, Boyle M, Sriranganathan N (2010). Brucellosis: a reemerging zoonosis. Veterinary Microbiology, 140(34): 392-398.

27. SANCO (Scientific Committee on Animal Health and Animal Welfare), (2001). Brucellosis in sheep and goats (Brucella melitensis). European Commission, Health and Consumer Protection Directorate- General. 
28. VSPT (Veterinary Services of Palestinian Territory), (1994). Prevention most important zoonosis. 1985-1994 Archive, unpublished.

29. WHO (World Health Organization), (1999). Human and animal brucellosis: Epidemiological Surveillance in the MZCP Countries. Report of a WHO/MZCP Workshop, Damascus, Syrian Arab Requblic, 4-5 May 1998. Athens 1999.
30. Yumuka Z, O'Callaghan D, (2012). Brucellosis in Turkey an overview. International Journal of Infectious Diseases. Doi: 10.1016/j.ijid.2011.12.011.

31. Zvizdic S, Cengic D, Bratic M, Mehanic S, Pinjo F, Hamzic S, (2006). Brucella melitensis review of the human infection case. Bosnian Journal of Basic Medical Sciences, 6: 15-18. 